\title{
Vulvar Lymphangitic Carcinomatosis: A Rare Metastasis from Gastric Adenocarcinoma
}

\author{
Amal Damiri ${ }^{1,2}$, Hafsa Chahdi, ${ }^{1,2}$, Mohamed Allaoui ${ }^{1,2}$, Abderrahim El Ktaibi, ${ }^{1,2}$, Mohamed \\ Reda El Ochi ${ }^{1,2}$, Mohamed Amine Essaoudi ${ }^{1,2^{*}}$ and Mohamed Oukabli,
}

${ }^{1}$ Department of Pathology, Mohamed V Military Hospital, Morocco

${ }^{2}$ Faculty of Medicine and Pharmacy, Mohammed V University, Morocco

*Corresponding author: Mohamed Amine Essaoudi, Department of Pathology, Mohamed V Military Hospital, Hay Riad, Rabat, Morocco; Faculty of Medicine and Pharmacy, Mohammed V University, Hay Riad, Rabat, Morocco

\begin{abstract}
Vulvar lymphangitic carcinomatosis (VLC) secondary to gastric carcinoma is a very rare entity. In this paper, we describe the clinical and pathological characteristics, evolution, of a patient with VLC of signet ring cell gastric adenocarcinoma. To our knowledge this is among the very rare reported cases in the literature.
\end{abstract}

\section{Introduction}

Vulva is an exceptional site for metastasis [1]. Common gynecological or non-gynecological malignancies can be the source of metastasis in vulva [2]. Presence of vulvar metastasis may initially be mistaken as a benign or a primary vulvar malignancy [3]. Differentiating primary and secondary vulvar malignancy is primordial because vulvar metastasis is often a pre-terminal phenomenon [4].

\section{Case Report}

A 32-year-old woman was admitted to the gynecology department to manage a vulvar mass that appeared 3 months ago. The clinical examination found nothing special, the gynecological examination showed a vulvar mass of about $5 \mathrm{~cm}$. A presumptive diagnosis of a benign lesion was made and a surgical decision to remove the mass was made.

Gross examination of the surgical specimen showed a firm gray mass at palpation measuring $5.8 \times 3.2 \mathrm{~cm}$ (Figure 1). Histologically, a squamous epithelium sur-

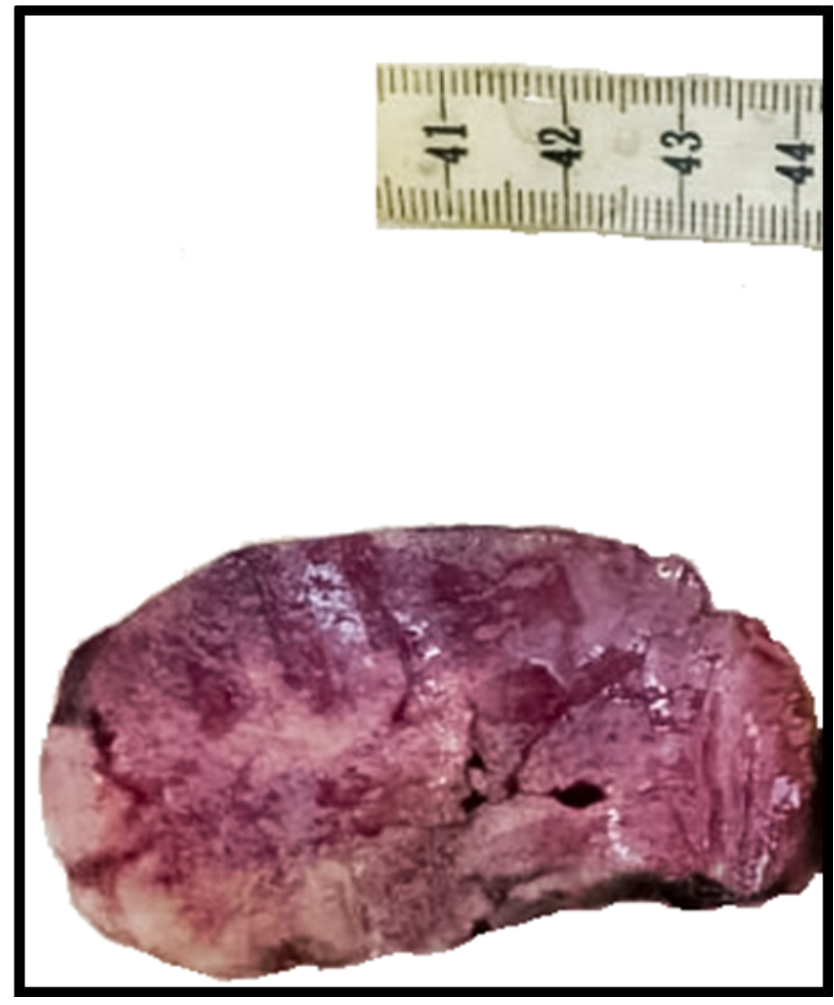

Figure 1: Gross examination showing a gray firm mass.

mounting a vessel-rich chorion was observed. These vessels contained in their lumen a carcinomatous proliferation made of abundant cytoplasmic cohesive cells, pushing the nucleus in the periphery and producing the appearance of signet ring cells (Figure 2 and Figure 3).

Citation: Damiri A, Chahdi H, Allaoui M, El Ktaibi A, El Ochi MR, et al. (2020) Vulvar Lymphangitic Carcinomatosis: A Rare Metastasis from Gastric Adenocarcinoma. Int J Pathol Clin Res 6:111. doi. org/10.23937/2469-5807/1510111

Accepted: July 20, 2020: Published: July 22, 2020

Copyright: (C) 2020 Damiri A, et al. This is an open-access article distributed under the terms of the Creative Commons Attribution License, which permits unrestricted use, distribution, and reproduction in any medium, provided the original author and source are credited. 


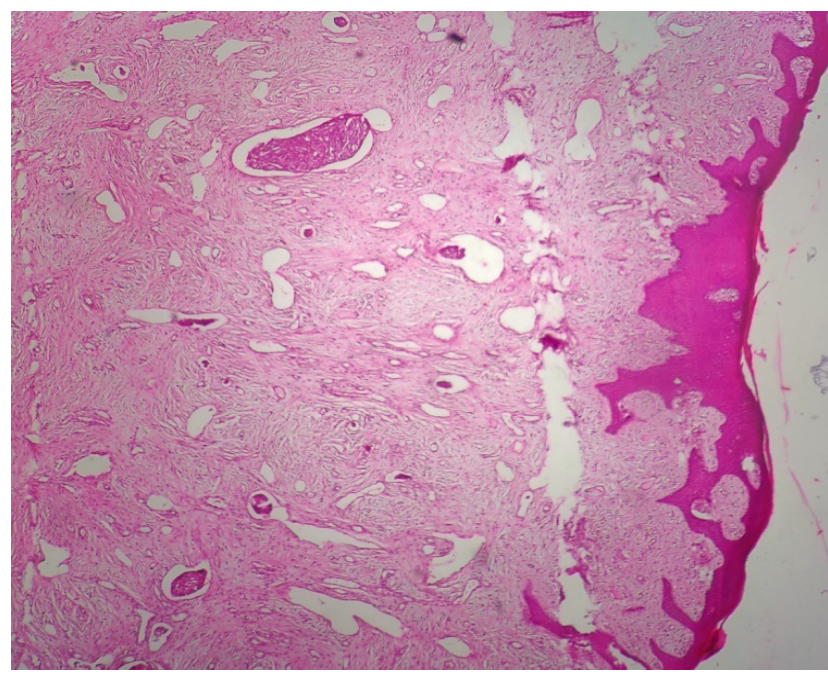

Figure 2: HEx10 showing intravascular tumor in the lamina propria.

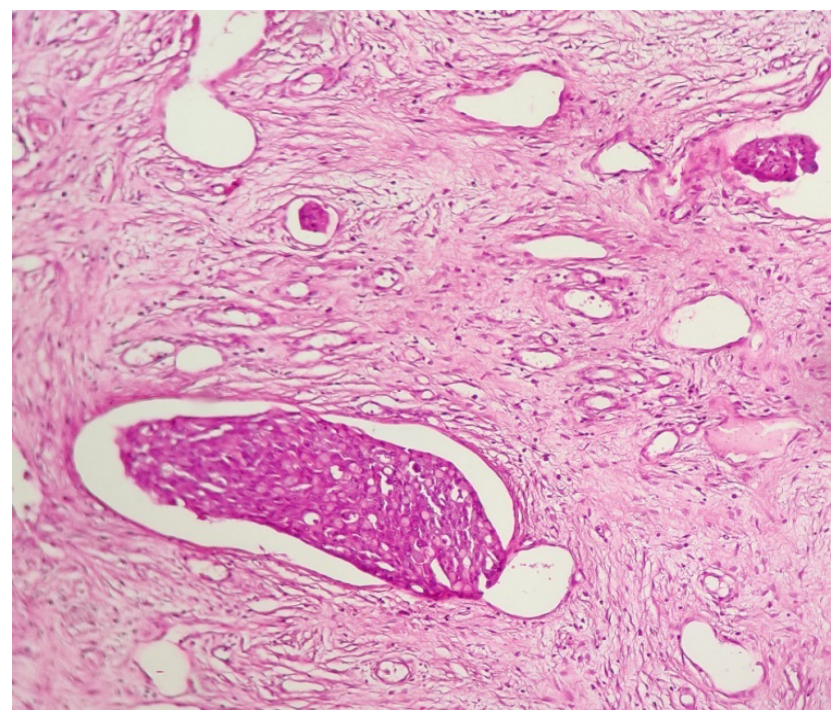

Figure 3: HEx25 showing signes rings cells in the lumina of vessels.

The immunoprofile of intravascular tumor cells showed a strong positivity for AE1/AE3 and a moderate positivity for CK7. CD 34 was positive in vessels (Figure 4, Figure 5 and Figure 6).

The diagnosis of a carcinomatous lymphangitis was made and the surgeon was informed of the diagnosis, which led to a more thorough examination which revealed that the patient was complaining of chronic epigastric pains resistant to conventional treatment. An endoscopy with gastric biopsy was made and returned in favor of a signet ring cell gastric adenocarcinoma.

\section{Outcomes}

After carrying out an extension assessment the computed tomography revealed nodules of peritoneal carcinosis, and the magnetic resonance imaging showed bilateral ovarian metastases.

The patient was put on palliative chemotherapy

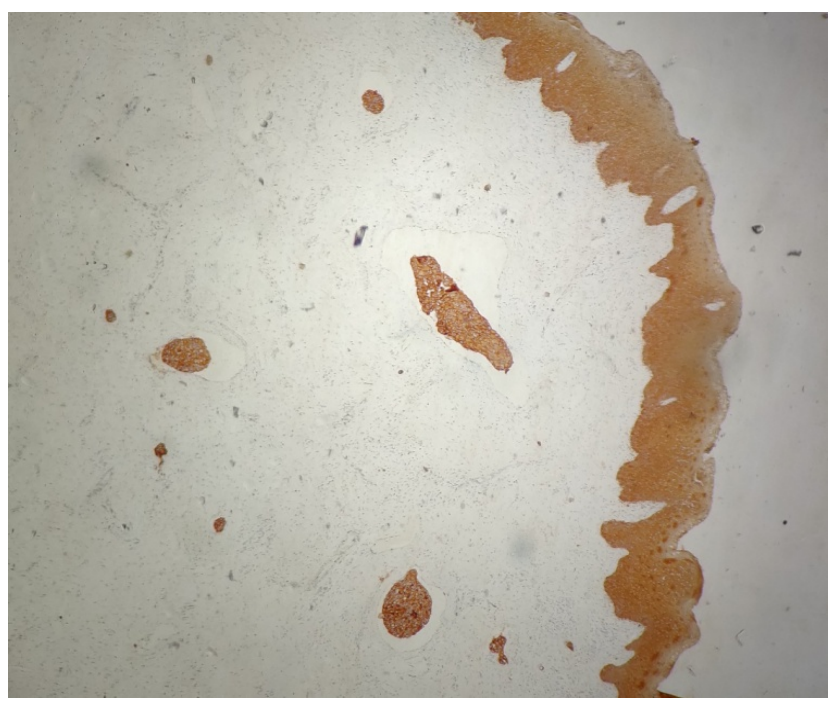

Figure 4: IHCx10 tumor cells are strongly positive for $\mathrm{AE} 1 /$ AE3.

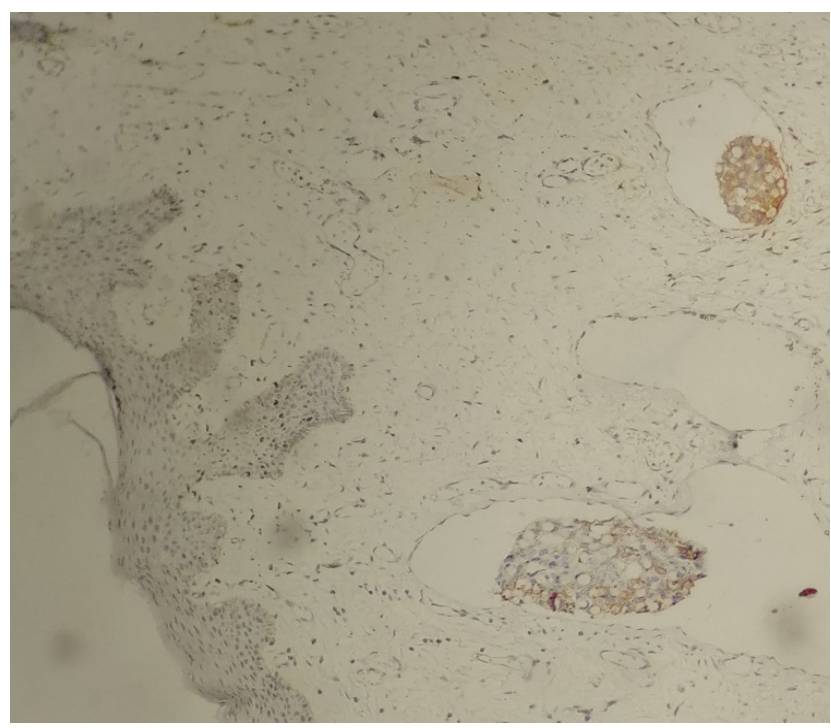

Figure 5: IHCX25 tumors cells are CK7 positive.

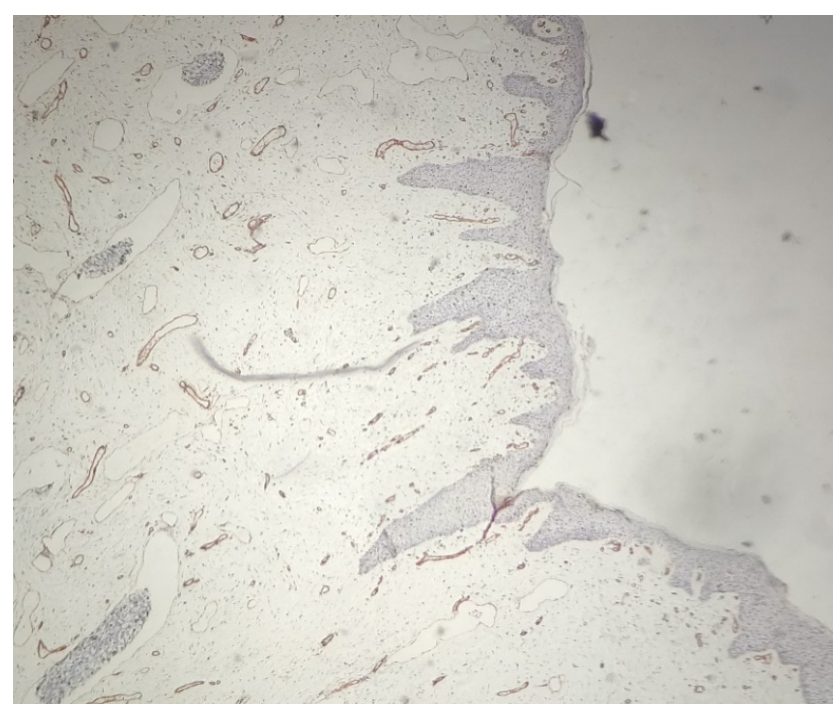

Figure 6: IHCx10 showing CD34 positive on the vessels.

with a cure every 2 weeks. 3 months later the patient 
presented a severe cough, a chest radiograph revealed bilateral hilar lymphadenopathy. The patient died 12 months later.

\section{Discussion}

The entire female genital tract is at risk for metastases occurrence from intragenital and extragenital primaries most commonly gastrointestinal adenocarcinomas [5]. The vulva is the least metastatic site of the female genital tract with the labia majora being the most common location [6]. It is noteworthy to mention that the occurrence of vulvar metastasis represents an end stage disease as it underlines, in general, a widespread incurable disease [2].

VLC is an invasion by tumor cells of the lymphatic vessels of the chorion. Clinically it can mimics benign lesion as angiomyofibroblastoma, cellular angiofibroma or hidradenoma papilliferum.

Neto, et al. reported the most common clinical presentation of vulvar metastasis occured in postmenopausal women (mean 54.8 years old) especially in labium majus mass [2]. Our case was also in labium majus but in young woman.

In both series reported by Neto and Mazur, malignant tumors that frequently give vulvar metastasis are from lower gastrointestinal tracts including colorectum and appendixsis. Our case was not consistent with this statistical finding and shows a gastric origin. Other primary malignancies in the breast, lung, appendix, and urinary system, as well as even lymphoma, have been reported $[2,5]$

\section{Conclusion}

VLC is not commonly observed. Despite its very low incidence, a precise etiological diagnosis of metastases is essential because the treatment and the prognosis are different. Therefore, metastases should also be suspected in patients with vulvar masses.

\section{Competing Interests}

The authors declare that they have no competing interests.

\section{References}

1. Dehner LP (1973) Metastatic and secondary tumors of the vulva. Obstet Gynecol 42: 47-57.

2. Neto AG, Deavers MT, Silva EG, Malpica A (2003) Metastatic tumors of the vulva: A clinicopathologic study of 66 cases. Am J Surg Pathol 27: 799-804.

3. Brand A, Scurry J, Planner R, Leung S (1996) Primary and recurrent colorectal cancer masquerading as gynaecological malignancy. Aust N Z J Obstet Gynaecol 36: 165-167.

4. RJ Kurman, ML Carcangiu, CS Herrinton, RH Young (2014) WHO classification of tumours of female reproductive organs. ( $4^{\text {th }}$ edn), IARC, Lyon, 253.

5. Mazur MT, Hsueh S, Gersell DJ (1984) Metastases to the female genital tract: Analysis of 325 cases. Cancer 53: 1978-1984

6. Lerner LB, Andrews SJ, Gonzalez JL, Heaney JA, Currie $\mathrm{JL}$ (1999) Vulvar metastases secondary to transitional cell carcinoma of the bladder: A case report. J Reprod Med 44: 729-732. 